\title{
Effects of Burkholderia thailandensis rhamnolipids on the unicellular algae Dunaliella tertiolecta
}

Article

Accepted Version

Charalampous, N., Grammatikopoulos, G., Kourmentza, C., Kornaros, M. and Dailianis, S. (2019) Effects of Burkholderia thailandensis rhamnolipids on the unicellular algae Dunaliella tertiolecta. Ecotoxicology and Environmental Safety, 182. 109413. ISSN 0147-6513 doi:

https://doi.org/10.1016/j.ecoenv.2019.109413 Available at https://centaur.reading.ac.uk/84941/

It is advisable to refer to the publisher's version if you intend to cite from the work. See Guidance on citing.

To link to this article DOI: http://dx.doi.org/10.1016/j.ecoenv.2019.109413

Publisher: Elsevier

All outputs in CentAUR are protected by Intellectual Property Rights law, including copyright law. Copyright and IPR is retained by the creators or other copyright holders. Terms and conditions for use of this material are defined in the End User Agreement. 


\section{CentAUR}

Central Archive at the University of Reading

Reading's research outputs online 
1 Effects of Burkholderia thailandensis rhamnolipids on the unicellular algae

2

Dunaliella tertiolecta

3

4 Nikolina Charalampous ${ }^{1}$, Giorgos Grammatikopoulos ${ }^{2}$, Constantina Kourmentza ${ }^{3}$, 5 Michael Kornaros ${ }^{4}$, Stefanos Dailianis ${ }^{1 *}$ 


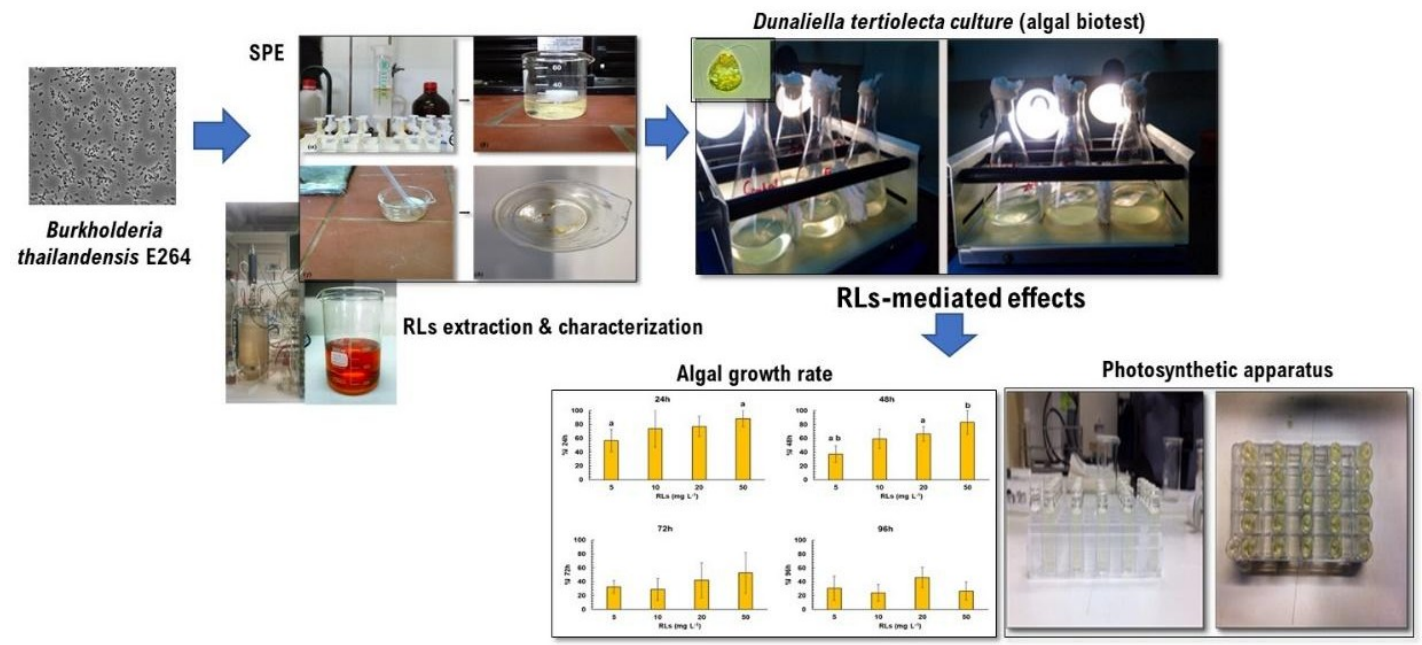

\section{Graphical abstract}




\section{Highlights}

- The effects of B. thailandensis rhamnolipids on D. tertiolecta were investigated.

- B. thailandensis predominant RL congener is the di-rhamnolipid Rha-Rha$\mathrm{C}_{14}-\mathrm{C}_{14}$

- Algal growth and photosynthetic parameters, using the JIP test, were tested.

- B. thailandensis rhamnolipids do not affect algal growth rate.

- RLs showed no significant effects on algae photosynthetic ability 
3

6 Nikolina Charalampous ${ }^{1}$, Giorgos Grammatikopoulos ${ }^{2}$, Constantina Kourmentza ${ }^{3}$, Michael Kornaros ${ }^{4}$, Stefanos Dailianis ${ }^{1 *}$

6

$7 \quad{ }^{1}$ Section of Animal Biology, Department of Biology, Faculty of Sciences, University of Patras, GR-26500, Patras, Greece.

$9{ }^{2}$ Laboratory of Plant Physiology, Section of Plant Biology, Department ofBiology, Faculty of Sciences, University of Patras, GR-26500, Patras, Greece.

${ }^{3}$ Department of Food \& Nutritional Sciences, School of Chemistry, Food and Pharmacy, University of Reading, RG6 6AP, Reading, UK

$13{ }^{4}$ Laboratory of Biochemical Engineering and Environmental Technology (LBEET), 14 Department of Chemical Engineering, University of Patras, Karatheodori 1 Str., GR26500 Patras, Greece

$17{ }^{*}$ Corresponding author:

Tel.: $+32610-969213$

19 E-mail: sdailianis@upatras.gr

20 Section of Animal Biology

21 Department of Biology

22 Faculty of Sciences, University of Patras 


\section{Abstract}

25 The effects of rhamnolipids (RLs) produced and further purified from Burkholderia 26 thailandensis, on the unicellular microalgae Dunaliella tertiolecta were investigated, 27 in terms of RLs ability to affect algal growth, photosynthetic apparatus structure and 28 energy flux, round and through photosystems II and I. Specifically, 24-48h RLs29 treated algae (RLs at concentrations ranged from 5 to $50 \mathrm{mg} \mathrm{L}^{-1}$ ) showed significantly 30 decreased levels of growth rate, while increased levels of $\mathrm{Chl} a$ and $\mathrm{b}$ were obtained 31 only in 72-96h RLs-treated algae. Similarly, although no changes were obtained in the

$32 \mathrm{Chl} \mathrm{a/b}$ ratio and almost all chlorophyll fluorescence parameters over time, yields of 33 electron transport $\left(\varphi \mathrm{R}_{0}, \varphi \mathrm{E}_{0}\right)$ and respective performance index $\left(\mathrm{PI}_{\text {total }}\right)$ were 34 negatively affected at 72 and $96 \mathrm{~h}$. Based on those findings, it seems that the inhibitory 35 effect of RLs on the algae growth rate after 24 and $48 \mathrm{~h}$ and the gradual attenuation of 36 the phenomenon (after $72 \mathrm{~h}$ of exposure), may indicate the initial response of the 37 organism, as well as algae ability to overcome, since RLs showed no effects on algae 38 photosynthetic ability. Those findings reveal for the first time that RLs from 39 Burkholderia thailandensis are not harmful for Dunaliella tertiolecta. However, 40 further studies with the use of more aquatic species could be essential for assessing 41 the RLs-mediated effects on aquatic biota.

43 Keywords: Algal growth, Burkholderia thailandensis, Dunaliella tertiolecta, Energy 44 flux, Photosynthetic apparatus, Rhamnolipids. 


\section{Introduction}

During the last decades, the production of microbial surfactants or biosurfactants by microorganisms is of great interest. Those surface-active compounds are considered as promising alternatives to chemical surfactants, due to their advantageous characteristics, such as their surface activity, $\mathrm{pH}$ tolerance, temperature, ionic strength, their biodegradability, low toxicity and emulsifying/demulsifying ability (Elshikh et al., 2017; Vijayakumar and Saravanan, 2015). Among the major groups of biosurfactants (i.e. low molecular mass glycolipids, like trehalolipids, sophorolipids, rhamnolipids and lipopeptides, as well as high molecular mass amphipathic polysaccharides, proteins, lipopolysaccharides, lipoproteins etc.), rhamnolipids (RLs) are of great importance, thus finding a wide range of applications, like functional food ingredients, detergents, fungicides and fertilizers, and also in cosmetic and pharmaceutical formulations and bioremediation (Müller et al., 2012; Kourmentza et al., 2017).

RLs are widely produced by the opportunistic pathogen Pseudomonas aeruginosa, due to its high production rates and space-time yields (Wittgens et al., 2011). However, the employment of such bacterial strains increases safety measures and process control requirements during fermentation, thus leading to the production of RLs from non-pathogenic strains belonging to Burkholderia species (Hörmann et al., 2010; Costa et al., 2011; Funston et al., 2016; Kourmentza et al. 2018). The latter process leads to the production of amphiphilic compounds comprising of one or two rhamnose molecules (mono- and/or di-RLs, respectively), linked glycosidically to one or two $\beta$-hydroxy fatty acids chains of $8-16$ carbon atoms (Abdel-Mawgoud et al., 2010; Kourmentza et al., 2017). RLs, occurred as secondary metabolites in the form of mixtures of different congeners (both mono- and di- RLs), can reduce the surface 
tension of water from 72 to $25-30 \mathrm{mN} \mathrm{m}^{-1}$ and the interfacial tension against hydrocarbons up to $1 \mathrm{mN} \mathrm{m}^{-1}$. Their critical micelle concentrations range between 10 $-225 \mathrm{mg} \mathrm{L}^{-1}$ and depend on the relative abundance of the congener mixtures and congener structures (Dubeau et al., 2009; Hörmann et al., 2010). They also act as emulsifiers, as they can form highly stable emulsions with various hydrocarbons and oils (Gudiña et al., 2016a), and as antibacterial, antifungal and antibiofilm agents (Borah et al., 2016; Elshikh et al., 2017).

The global market of RLs, and biosurfactants in general, is expected to reach 5.5,2 Billion USD by 2022, with the RLs segment projected to grow at the highest Compound Annual Growth Rate (CAGR) during the forecast period between 2017 and 2022 (Markets and Markets, 2017). Moreover, the fact that the segment regarding the application of agricultural chemicals is also expected to grow at the highest CAGR within the same period, highlights the necessity of 'green' alternatives, such as biosurfactants, used in crop control and indirect plant growth promotion. In this light, the likelihood of those compounds, like RLs, to end up in aquatic environments (i.e. with sewage water) as well as their potential effects is of great concern (Johann et al., 2016).

Since reports on the environmental effects of such biosurfactants are limited, studies concerning their impact on aquatic producers, such as algae, that possess key position in the trophic chain via the production of high amounts of oxygen and their participation in nutrient cycles (DeLorenzo, 2009; Ma et al., 2010; Perreault et al., 2012) are needed. Among algae species, frequently used in biotests for assessing the relative toxicity of various chemicals and/or waste discharges, the green microalgae Dunaliella tertiolecta fulfills most of the criteria for a bioassay organism (i.e. cultivation in the laboratory, rapid growth, acute response to environmental stressors) 
and has been proposed as a standard organism for ecotoxicological tests (US EPA, 1974; APHA, 1989; ASTM, 1996; OECD, 2011). In fact, studies regarding the investigation of osmoregulation mechanism, carotenoid production, and photosynthesis under extreme conditions have been performed so far, using species of the genus Dunaliella (Oren, 2005), while a lot of studies reported a battery of algal growth and survival endpoints (i.e. cell density, growth rate and chlorophyll content) as useful indices for assessing functional and structural effects due to environmental stressors (Oren, 2005; DeLorenzo, 2009; Tsiaka et al., 2013; Tsarpali et al., 2016).

Given that the photosynthetic apparatus is a common target of environmental stress, the determination of chlorophyll a $(\mathrm{Chl} \mathrm{a)} \mathrm{fluorescence} \mathrm{has} \mathrm{been} \mathrm{recognized} \mathrm{as}$ a useful tool in sensing stress of photosynthetic organisms widely used in ecotoxicological bioassays (Zhou et al., 2006; Ralph et al., 2007; Kumar et al., 2014). Specifically, the impact sites can be related to simple structural characteristics such as photosynthetic pigment concentrations and ratios, or to functional properties of PSII and PSI such as antenna performance, electron transport efficiency etc. The most used parameters are maximum and effective quantum yield ( $\mathrm{Fv} / \mathrm{Fm}$ and $\Delta \mathrm{F} / \mathrm{Fm})$ and nonphotochemical quenching (NPQ) (Kumar et al., 2014). Lately, the fast fluorescence induction kinetics of $\mathrm{Chl}$ a have been also adopted for ecotoxicology tests (Dewez et al., 2008; Saison et al., 2010; Invally et al., 2017). The signal is the record of fluorescence rise from its minimum in the dark-adapted state, to its maximum, after a saturating pulse. The analysis of polyphasic curves (JIP-test) offers many parameters, each of them related to a step of the energy flux round and between the photosystems (Strasser et al., 2000, 2004). Consequently, the sensitivity of this technique is expected to be high, as the impact site of a tested substance could be related to any of those steps but not to the total process. To our knowledge, despite the fact that 
chlorophyll fluorescence has been widely used for two decades in ecotoxicology studies (Ralph et al., 2007; Kumar et al., 2014 and references there-in), the JIP-test has been sporadically used the last years (Appenroth et al., 2001; Geoffroy et al., 2003; Xia and Tian, 2009) and only in one study regarding impact of a chemical surfactant on wheat plants (Sharma et al., 2018).

Based on the imperative need for investigating RLs complex mixtures instead of single RLs components (Johann et al., 2016) into aquatic ecosystems, the present study aimed to investigate the potential effects of Burkholderia thailandensis produced and further purified RLs congeners on the unicellular microalgae Dunaliella tertiolecta. In this context, algal growth and/or inhibition rates were estimated in RLstreated algae, while parameters commonly related with the photosynthetic apparatus, such as $\mathrm{Chl}$ a, $\mathrm{Chl}$ b, total chlorophyll, total carotenoids, as well as chlorophyll fluorescence parameters of photosynthetic systems I and II (PSI \& PSII) were further investigated by the JIP-test for the first time.

\section{Materials and Methods}

2.1. Bacterial strain and cultivation conditions

The production of RLs was performed as previously described by Kourmentza et al. (2018). In brief, Burkholderia thailandensis E264 was grown on nutrient broth, supplemented with $4 \% \mathrm{w} / \mathrm{v}$ of used cooking oil (sunflower) as the sole carbon source. Cultivation took place in a $10 \mathrm{~L}$ bioreactor with a working volume of $8 \mathrm{~L} . \mathrm{pH}$ was controlled to 7.0 by the automatic addition of base $(5 \mathrm{M} \mathrm{NaOH})$ or acid $(2 \mathrm{M} \mathrm{HCl})$, temperature was kept at $37 \pm 0.1{ }^{\circ} \mathrm{C}$, air supply was constant at $1 \mathrm{vvm}$, and DO level was maintained at $20 \%$ of air saturation by automatically adjusting the stirring rate. Foam formation, due to RLs production, was managed by mounting of a 
145 polyetheretherketon (PEEK) disc to the agitator shaft that served as a mechanical

146 foam destroyer. An antifoam sensor was also installed, in case of excessive foaming,

147 that suppressed foam formation by the addition of Antifoam A agent. At the end of

148 the cultivation the culture broth was collected and further treated for RLs extraction

149 and purification.

\subsection{Rhamnolipid extraction and purification}

At the end of the cultivation the culture broth was collected, and the cell-free

153

\subsection{Rhamnolipids characterization}

RLs characterization and relative abundance between different congeners was performed as previously described by Kourmentza et al. (2018). Liquid 
Chromatography (Finningan Surveyor) equipped with a C8 reverse phasecolumn (Vydac ${ }^{\circledR}$ 208TP C8, ID $2.1 \times \mathrm{L} 150 \mathrm{~mm}, 5 \mu \mathrm{m}$ ) and a diode array detector (DAD) coupled with a Thermo Finningan LCQ DECA XP MAX quadropole ion trap mass spectrometer (MS), in negative electrospray ionization mode, was performed. RLs mixtures of high purity ( $\sim 95 \%)$, one dominant in the mono-RL $\mathrm{C}_{10}-\mathrm{C}_{10}$ and another one dominant in the di-RL $\mathrm{C}_{10}-\mathrm{C}_{10}$, were used for the calibration curves (R95D90/ R95M90, AGAE Technologies), in the same range of concentrations, and the results were expressed as equivalents of these standards.

\subsection{Algal biotest}

The green algae Dunaliella tertiolecta (strain CCAP 19/6B, from Scottish Marine Institute, Oban, Argyll, Scotland) was cultivated in f/2 medium without Si (24 $\pm 1^{\circ} \mathrm{C}, \mathrm{pH} 8.3 \pm 0.3,86 \pm 8.6 \mu \mathrm{E} / \mathrm{m}^{2} / \mathrm{s}$ fluorescent lighting) (OECD, 2011). At late logarithmic phase, $1 \times 10^{4}$ cells $\mathrm{mL}^{-1}$ were transferred to conical sterilized flasks, containing freshly prepared culture medium (final volume $200 \mathrm{~mL}$ ) and further treated with different concentrations of $\operatorname{RLs}\left(5,10,20\right.$ and $\left.50 \mathrm{mg} \mathrm{L}^{-1}\right)$ for $96 \mathrm{~h}$. Those RLs concentrations tested are referred as "nominal" concentrations, since there is no data regarding RLs solubility into the culture medium, as well as RLs ability to bind to culture medium compounds and culture flask cell walls as previously mentioned (Tsarpali et al., 2016). On the other hand, the range of RLs currently tested was almost like those previously reported to other species tested (see for example Sydow et al., 2018; Wang et al., 2005; Gustafsson et al., 2009; Johann et al., 2016).

Every $24 \mathrm{~h}$, algal cell number, growth rate $(\mu)$ and inhibition rate $(\% \mathrm{I})$ were counted/determined according to well-known equations (for further details see SM 
2.4). Two independent experiments were performed and RLs concentrations were tested in duplicate per experiment.

In parallel, parameters commonly related with the photosynthetic ability of algae, such as the contents of $\mathrm{Chl} \mathrm{a,} \mathrm{Chl} \mathrm{b}$, total chlorophyll, total carotenoids, as well as chlorophyll fluorescence parameters indicative of the physiological status of photosynthetic systems I and II (PSI \& PSII) were also measured.

\subsection{Determination of chlorophyll content and total carotenoids} $10 \mathrm{~mL}$ of each culture (RLs- and RLs-free algal cultures) were transferred in Falcon tubes every $24 \mathrm{~h}$. All samples were centrifuged at $4000 \mathrm{x}$ g for $10 \mathrm{~min}$ and the supernatant was carefully discarded. Packed cells were diluted initially with $1 \mathrm{~mL}$ dimethyl-formamide (DMF) to a final volume of $4 \mathrm{ml}$. After an incubation period of $20 \mathrm{~min}$, samples were centrifuged as mentioned above, and the supernatant was used for spectrophotometric analysis (Shimadzu UV-VIS 160A Spectrophotometer, Shimadzu Corporation, Tokyo) at 480, 647, 664 and $750 \mathrm{~nm}$.

Chl a, Chl b and total carotenoids content $\left(\mu \mathrm{g} \mathrm{mL} \mathrm{m}^{-1}\right)$ was calculated using the Lambert-Beer based equations (3-5) (Wellburn, 1994) (for further details see SM 2.5).

\subsection{Chlorophyll fluorescence measurements and JIP-test}

Fast Chl a fluorescence transient was captured by a portable fluorimeter

(Handy-PEA, Hansatech Instruments Ltd. King's Lynn Norfolk, UK). Measurements were conducted on dark adapted samples $(2 \mathrm{~mL}$ of RLs- and RLs-free algal culture in each case, 15 min adaptation time) and the filtered medium for each treatment served as the blank. A bank of three red LEDs (peak at $650 \mathrm{~nm}$ ) providing $3000 \mu \mathrm{mol} \mathrm{m}^{-2} \mathrm{~s}^{-1}$, was used for excitation. Fluorescence was recorded from $10 \mu$ s to $2 \mathrm{~s}$ with intervals of 
$21910 \mu \mathrm{s}, 100 \mu \mathrm{s}, 1 \mathrm{~ms}, 10 \mathrm{~ms}$ and $100 \mathrm{~ms}$ between the readings, for time periods of $10-$ $220300 \mu \mathrm{s}, 0.3-3 \mathrm{~ms}, 3-30 \mathrm{~ms}, 30-300 \mathrm{~ms}$, and 0.3-2 s, respectively. Fluorescence data 221 were then transformed in a logarithmic time scale and the derived polyphasic curve, 222 was analyzed according to JIP-test (Strasser et al., 1995) as extended to analyze 223 events around PSI (Oukarroum et al., 2009; Stirbet and Govindjee, 2011). The 224 parameters which were used for the photosynthetic analysis were: maximum quantum 225 yield of primary PSII photochemistry $\varphi \mathrm{P}_{0}=\mathrm{F}_{\mathrm{V}} / \mathrm{F}_{\mathrm{M}}$; quantum yield of the electron 226 transport flux from $\mathrm{Q}_{\mathrm{A}}$ to $\mathrm{Q}_{\mathrm{B}}, \varphi \mathrm{E}_{0}$; quantum yield for reduction of end electron 227 acceptors at the PSI acceptor side $\varphi R_{0} ; 1-\mathrm{V}_{\mathrm{I}}$, a parameter related to the size of the 228 pools of final PSI electron acceptors and potential for energy conservation from 229 exciton to the reduction of PSI end acceptors $\mathrm{PI}_{\text {total }}$.

$231 \quad 2.7 \quad$ Statistical analysis

232 The estimation of RLs concentration that cause $50 \%$ inhibition of algae growth 233 (IC $\mathrm{I}_{50}$ endpoints) and their 95\% confidence intervals (CI) in each case was performed 234 with the use of Probit analysis ( $<<0.05$, IBM SPSS 19 Inc. software package). After 235 checking for homogeneity of variance (Levene's test of equality of error variances), 236 the significant differences among parameters were tested with the use of Mann237 Whitney u-test $(\mathrm{p}<0.05)$.

239 3. Results

$240 \quad 3.1 \quad$ RLs-mediated effects of Dunaliella tertiolecta growth rate

241 LC/MS analysis on the RLs produced (data not shown; for further details see

242 Kourmentza et al., 2018) revealed a narrow range of different RLs congeners, 243 dominant in di-RLs. Specifically, RLs consisted of four congeners; the di-RL Rha- 
244 Rha- $\mathrm{C}_{14}-\mathrm{C}_{14}$ with the highest abundance $(71.40 \%)$, the di-RL Rha-Rha- $\mathrm{C}_{12}-\mathrm{C}_{14}$, the 245 di-RL Rha-Rha- $\mathrm{C}_{14}-\mathrm{C}_{16}$ (or Rha-Rha- $\mathrm{C}_{16}-\mathrm{C}_{14}$ ) and the mono-rhamnolipid Rha- $\mathrm{C}_{14}-\mathrm{C}_{14}$ $246(14.09,7.56$, and $6.94 \%$ abundance, respectively). Based on the latter, the algal 247 bioassay showed that those RLs (at concentrations ranged from 5 to $50 \mathrm{mg} \mathrm{L}^{-1}$ ), can 248 alter algal growth rates, thus inhibiting their growth at least at 24 and $48 \mathrm{~h}$, followed 249 by a significant attenuation of the adverse effects over time (72 and 96h) (Fig 1, Table 250 1). The latter is more obvious taking in mind the estimated $24-96 \mathrm{~h} \mathrm{IC}_{50}$ values (Table 251 2) that shows a significant attenuation of RLs ability to inhibit algal growth rate over 252 time

3.2 RLs-mediated effects on photosynthetic apparatus of Dunaliella tertiolecta

Algae treated with RLs for 96h showed significant increase of Chl a, Chl b, total

256 Chl and carotenoids levels, irrespectively of the RLs concentration (Fig 2a-b, 3-4).

257 The increase of each photosynthetic pigment content per cell was of the same 258 magnitude, therefore, $\mathrm{Chl} \mathrm{a} / \mathrm{b}$ and $\mathrm{Car} / \mathrm{Chl}$ ratios did not change (SM Fig 1, 2). The 259 elevated values in the presence of RLs were not detected at 24, 48 and $72 \mathrm{~h}$. In fact, 260 pigment contents doubled their concentrations in both control and treatments at $48 \mathrm{~h}$, 261 while at $72 \mathrm{~h}$, control values were partly reduced only in control and the significant 262 differences between treatments and control revealed at $96 \mathrm{~h}$.

The fluorescence measurements in the present study (Table 3), indicated that

264 yield $\left(\varphi \mathrm{E}_{0}\right)$ related to electron transport up to $\mathrm{Q}^{-} \mathrm{A}$ as well as the pool of end electron 265 acceptors of PSI $\left(1-\mathrm{V}_{\mathrm{I}}\right)$ were decreased by the highest concentration of RLs at $96 \mathrm{~h}$. 266 Yield for reduction of end electron acceptors at the PSI acceptor side $\left(\varphi R_{0}\right)$ was 267 significantly reduced by the two highest concentrations of RLs (20 and $\left.50 \mathrm{mg} \mathrm{L}^{-1}\right)$. 
268 The $\mathrm{PI}_{\text {total }}$ index showed the highest sensitivity, being reduced even at $10 \mathrm{mg} \mathrm{L}^{-1}$ of 269 RLs (Table 3).

270 4. Discussion

271 To our knowledge, this is the first study regarding the investigation of $B$.

272 thailandensis RLs effects on the unicellular microalgae Dunaliella tertiolecta. The 273 current non-pathogenic species has been reported to be an efficient producer of di274 RLs, as revealed by the abundances of di- and mono-RLs currently determined, which 275 are composed by longer chain length fatty acid moieties, instead of the opportunistic 276 pathogen $P$. aeruginosa that produces RLs congeners with the most abundant being 277 the mono- RL Rha- $\mathrm{C}_{10}-\mathrm{C}_{10}$, followed by di-RL Rha-Rha- $\mathrm{C}_{10}-\mathrm{C}_{10}$ and mono-RL Rha$278 \mathrm{C}_{10}$ (Gudiña et al., 2016b). Those structural differences between RLs congeners are 279 attributed to the significant differences in the amino acid sequences of $r h l A, r h l B$ and $280 r$ rlh $C$ genes (Funston et al., 2016). However, RLs produced by B. thailandensis and $P$. 281 aeruginosa can find different areas of applications due to their different composition 282 that affects their properties and therefore their behavior as biosurfactants, emulsifying 283 agents etc. (Kourmentza et al., 2017).

4.1 RLs-mediated effects on algal growth

Given that algae are considered as ideal early warning biological systems for

287 assessing any aquatic disturbances, as well as that algal biotests are preferable for 288 ethical and economic reasons (Bae and Park, 2014), the present study revealed the 289 effect of $B$. thailandensis RLs congeners on the unicellular algae Dunaliella 290 tertiolecta. The results showed for the first time that RLs at concentrations ranged 291 from 5 to $50 \mathrm{mg} \mathrm{L}^{-1}$ can cause algal growth inhibition at 24 and $48 \mathrm{~h}$, with a 292 concomitant recovery over time. Those RLs concentrations currently used are lower 
293 than those previously used for performing algal biotests, using other algal strains

294 (Wang et al., 2005; Gustafsson et al., 2009).

Although studies regarding the effects of B. thailandensis derived RLs are still

296 lacking, the results of the present study seem to be in accordance with previous

297 studies, concerning the effects of RLs on different species. Specifically, mono-RLs

298 (Rha- $\mathrm{C}_{10}-\mathrm{C}_{10}$ ) were found to be less toxic than those occurred by chemical surfactants,

299 like SDS, on Daphnia magna $\left(24 \mathrm{~h} \mathrm{EC}_{50}=50 \mathrm{mg} \mathrm{L}^{-1}, 48 \mathrm{~h} \mathrm{EC}_{50}=30 \mathrm{mg} \mathrm{L}^{-1} ; 3-100\right.$

$300 \mathrm{mg} \mathrm{L}^{-1}$ concentration tested) and Danio rerio $\left(\mathrm{LC}_{50}=60 \mathrm{mg} \mathrm{L}^{-1} ; 2-200 \mathrm{mg} \mathrm{L}^{-1}\right.$

301 concentration tested), (Braunbeck et al., 2005; Johann et al., 2016). Moreover,

302 Pseudomonas aeruginosa derived RLs showed significantly reduced levels of growth

303 rates on harmful algal blooms (HAB) species Alexandrium minutum and Karenia

304 brevis (Dinophyceae) even after their exposure to RLs at concentration of $5 \mathrm{mg} \mathrm{L}^{-1}$ for

30524 h (Wang et al., 2005; Gustafsson et al., 2009), which is in accordance with the

306 results of the present study. However, according to EC Regulation 1272/2008 (OJL

$307353,2008)$, B. thailandensis derived RLs currently tested showed high $\mathrm{IC}_{50}$ values

308 [i.e. $72 \mathrm{~h} \mathrm{IC} 50=44.57 \mathrm{mg} \mathrm{L}^{-1}(25.466-212.882)$ and $96 \mathrm{~h}_{50}>1000 \mathrm{mg} \mathrm{L}^{-1}$ ], thus

309 indicating low harmful effects on marine biota, at least in case of algae species. The

310 latter could be due to RLs high solubility (almost negative log Kow values) and

311 degradation (Kłosowska-Chomiczewska et al., 2017), as well as to species sensitivity

312 and acclimation with time. In fact, it is known that crude RLs are soluble in aqueous

313 solutions at $\mathrm{pH}$ 7-7.5, while di-RLs are expected to be more soluble in water

314 compared to mono-RLs since they consist of two rhamnose molecules instead of one

315 (Abdel-Mawgoud at el., 2009). Moreover, in contrast to di-RLs, mono-RLs

316 complexes cadmium 10 times more strongly (unpublished data), is a more powerful

317 solubilizing agent, has lower water solubility, and sorbs to surfaces more strongly 
318 (Zhang et al., 1997). In parallel with the synergistic/antagonistic effects of RLs 319 congeners previously mentioned, the obtained results (i.e. growth rate and/or \%I) 320 could be over- or under- estimated in some extent, due to the absence of data 321 regarding RLs congeners solubility into the culture medium as well as their ability to 322 bind to culture medium compounds and culture flask walls, that could decrease RLs 323 effective concentration (Kramer et al., 2012; Tsarpali et al., 2016). Additionally, 324 regarding species sensitivity and acclimation, it has been reported that the presence of 325 cell wall could be linked with low algal vulnerability, while algae with no cell wall,

326 like Dunaliella tertiolecta, could be sensitive to surfactants and other chemical 327 substances, revealing low growth rates after a short period of exposure (Gong et al., 328 2004), as well as growth rate recovery over time due to adaptation and metabolic 329 regulations, mainly related with detoxification and algal survival under stressed 330 conditions (Poremba et al., 1991; Maslin and Maier, 2000; Nikookar et al., 2005; 331 Zeng et al., 2007; Wen et al., 2009; Tsiaka et al., 2013). However, more studies are 332 needed for elucidating the exact mode of RLs action in algae.

$334 \quad 4.2$ RLs-mediated effects on algal photosynthetic apparatus

335 It is known that algae can adjust their intracellular concentration of chlorophylls 336 and carotenoids in response to properties of their culture medium and to 337 environmental conditions. In addition, the light intensity and nutrient availability are 338 the predominant factors influencing photosynthetic pigment concentration and as an 339 adaptive response, pigments are increasing under low light intensity or nutrient 340 transient starvation (Kana et al., 1997; Young and Beardall, 2003; da Silva Ferreira 341 and Sant'Anna, 2017). Based on the latter, the fluctuation of Chl/cell and 342 carotenoids/cell currently observed in control cells can be attributed to acclimation of 
343 the algae in the new culture medium after inoculation, while the light or nutrient

344 starvation seemed to cause negligible effects, at least under such a short-term culture

345 treatment $(0-96 \mathrm{~h})$. On the other hand, it is therefore most likely that RLs counteracted

346 any temporal environmental pressure through modification of membrane

347 permeability, since it is known that smalls changes in RLs-treated algal surface

348 tension could lead to slight alterations of membrane permeability, preserving or even

349 stimulating pigment formation (Sharma et al., 2018), which in turn could stimulate the 350 growth of cell culture (Lowe et al. 1994).

351 Given that a surfactant can affect thylakoid membranes without affecting

352 pigments of the light harvesting complexes (Markwell and Thornber, 1982), the

353 results of the present study showed that the only negative impact of RLs on

354 photosynthetic processes carried out on thylakoid membranes was related to electron

355 transport round and between PSII and PSI $\left(\varphi \mathrm{E}_{0}, \varphi \mathrm{R}_{0}\right)$ and the pool of the final

356 electron acceptors at PSI $\left(1-\mathrm{V}_{\mathrm{I}}\right)$. The $\mathrm{PI}_{\text {total }}$ incorporates yields of electron transport

357 together with parameters related to flux of energy in light harvest complex and $\mathrm{RC}$ of

358 PSII, thus proving a sensitive tool for a variety of stresses in photosynthetic

359 autotrophs (Strasser et al. 2000; Ralph et al. 2007; Koutra et al. 2018). Actually, in the

360 present study, $\mathrm{PI}_{\text {total }}$ appears as the most sensitive index of the JIP-test, influenced at

361 even lower concentration of RLs, at which any effect on partial electron transport

362 processes cannot be detected.

363 According to previous studies, the most important effect of surfactants on algal

364 cell is the biolytic one. Apart from plasma membrane denaturation which leads to cell

365 lysis, they can cause partial disintegration of the membrane, changing its permeability

366 and facilitating their entrance inside the cell, where they can affect almost every

367 organelle, chloroplast ultrastructure, thylakoid organization, and chlorophyll 
biosynthesis (Wang et al., 2005; Popova and Kemp, 2007; Vonlanthen et al., 2011).

369 However, the present study showed that relevant effects could be recorded only at 370 relatively high concentrations of RLs. In fact, the critical micelle concentration for

371 RLs depends on their structure and abundant congener, and may range between 10$372225 \mathrm{mg} \mathrm{L}^{-1}$ (Dubeau et al., 2009; Sobrinho et al., 2013). For the case of RLs produced 373 by $B$. thailandensis, that are mainly composed by $\mathrm{Rha}-\mathrm{Rha}-\mathrm{C}_{14}-\mathrm{C}_{14}$, the critical 374 micelle concentration was found to be around $225 \mathrm{mg} \mathrm{L}^{-1}$ (Kourmentza et al., 2018). 375 In this context, the possibility of worsening or amelioration of impact on electron 376 transport processes later than $96 \mathrm{~h}$ needs further experimentation, while low 377 concentrations of RLs could be even protective for some aspects of acclimation of the 378 photosynthetic machinery.

379

380

392

\section{Conclusions}

The effects of RLs congeners from the bacteria Burkholderia thailandensis on the growth and the photosynthetic apparatus of the green alga Dunaliella tertiolecta were investigated for the first time. The $96 \mathrm{~h}$ algal biotest currently performed using different concentrations of RLs revealed a decrease in the growth rate of the microalgae at 24 and $48 \mathrm{~h}$, followed by a significant recovery with time ( $72 \mathrm{~h}$ and 96 h), thus indicating low RLs-mediated harmful effects. Additionally, the negligible impact of RLs on the photosynthetic apparatus of Dunaliella tertiolecta revealed for the first time, thus serving as a useful tool for assessing the applicability and usage of B. thailandensis RLs in a battery of processes over other environmentally harmful surfactants. Moreover, the PItotal parameter of the JIP-test appeared as the most sensitive index of any impact on photochemical process. However, more studies using (a) a battery of aquatic species and (eco)toxicological tests, (b) sophisticated 
393 analytical methods for the determination and prediction of the transport and fate of

394 RLs into the aquatic media, and (c) complex mixtures of RLs and environmental 395 contaminants could be of great concern for elucidating RLs environmental footprint. 
397 Dr. Constantina Kourmentza acknowledges the financial support provided by the 398 European Commission through the FP7-PEOPLE- 2013-IEF-Marie-Curie Action: 399 Intra-European Fellowships for Career Development (Project ID: 625774).

400

401 Conflict of interest

402 Authors declare no conflict of interest.

403

404 References

405 Abdel-Mawgoud, A.M., Aboulwafa, M.M., Hassouna, N. A-H., 2009. 406 Characterization of rhamnolipid produced by Pseudomonas aeruginosa isolate 407 Bs20. Appl. Biochem. Biotechnol. 157, 329-345.

408

Abdel-Mawgoud, A.M., Lépine, F., Déziel, E., 2010. Rhamnolipids: Diversity of

409 structures, microbial origins and roles. Appl. Microbiol. Biotechnol. 86, 1323-

410 1336.

411 APHA, 1989. Toxicity testing with phytoplankton. Standard Methods for 412 Examination of Water and Wastewater, $17^{\text {th }}$ Ed., Suppl. Washington, DC. USA. 413 Appenroth, K.J., Stöckel, J., Srivastava, A., Strasser, R.J., 2001. Multiple effects of 414 chromate on the photosynthetic apparatus of Spirodela polyrhiza as probed by 415 OJIP chlorophyll a fluorescence measurements. Environ. Pollut. 115(1), 49-64. 416 American Society for Testing and Materials, 1996. Standard guide for conducting 417 static 96-h toxicity tests with microalgae. Vol. 11.05, ASTM, West 418 Conshohocken, PA. USA. 
Bae, M.J., Park, Y.S., 2014. Biological early warning system based on the responses of aquatic organisms to disturbances: A review. Sci. Total Environ. 466-467, 635-649.

Borah, S.N., Goswami, D., Sarma, H.K., Cameotra, S.S., Deka, S., 2016. Rhamnolipid biosurfactant against Fusarium verticillioides to control stalk and ear rot disease of maize. Front. Microbiol. 7, 1-10.

Braunbeck, T., Böttcher, M., Hollert, H., Kosmehl, T., Lammer, E., Leist, E., Rudolf, M., Seitz, N., 2005. Towards an alternative for the acute fish LC (50) test in chemical assessment: the fish embryo toxicity test goes multi-species—an update. ALTEX 22, 87-102.

Costa, S.G., Déziel, E., Lépine, F., 2011. Characterization of rhamnolipid production by Burkholderia glumae. Lett. Appl. Microbiol. 53, 620-627.

da Silva Ferreira, V., Sant'Anna, C., 2017. Impact of culture conditions on the chlorophyll content of microalgae for biotechnological applications. World J. Microbiol. Biotechnol. 33, 20. https://doi:10.1007/s11274-016-2181-6.

DeLorenzo, A.M., 2009. Utility of Dunaliella in ecotoxicity testing, in: Ben-Amotz, A., Polle, J.E.W., Rao, D.V.S. (Eds.), The alga Dunaliella: biodiversity, physiology, genomics and biotechnology, Science Publishers, Enfield, pp. 495512.

Dewez, D., Didur, O., Vincent-Héroux, J., Popovic, R., 2008. Validation of photosynthetic-fluorescence parameters as biomarkers for isoproturon toxic effect on alga Scenedesmus obliquus. Environ. Pollut. 151(1), 93-100.

Dubeau, D., Déziel, E., Woods, D.E., Lépine, F., 2009. Burkholderia thailandensis harbors two identical rhl gene clusters responsible for the biosynthesis of rhamnolipids. BMC Microbiol. 9, 263. 
Elshikh, M., Funston, S., Chebbi, A., Ahmed, S., Marchant, R., Banat, I.M., 2017. Rhamnolipids from non-pathogenic Burkholderia thailandensis E264: Physicochemical characterization, antimicrobial and antibiofilm efficacy against oral hygiene related pathogens. N. Biotechnol. 36, 26-36.

Funston, S.J., Tsaousi, K., Rudden, M., Smyth, T.J., Stevenson, P.S., Marchant, R., Banat, I.M., 2016. Characterising rhamnolipid production in Burkholderia thailandensis E264, a non-pathogenic producer. Appl. Microbiol. Biotechnol. 100, 7945-7956.

Geoffroy, L., Dewez, D., Vernet, G., Popovic, R., 2003. Oxyfluorfen toxic effect on $S$. obliquus evaluated by different photosynthetic and enzymatic biomarkers. Arch. Environ. Contam. Toxicol. 45(4), 445-452.

Gong, L.Y., Li, Y.B., Wang, X.L., Liang, S.K., Zhu, C.J., Han, X.R., 2004. The influence of biosurfactant on the growth of Prorocentrum donghaiense. China Environmental Science, 6.

Gudiña, E.J., Rodrigues, A.I., Alves, E., Domingues, M.R., Teixeira, J.A., Rodrigues, L.R., 2016a. Bioconversion of agro-industrial by-products in rhamnolipids toward applications in enhanced oil recovery and bioremediation. Bioresour. Technol. 177, 87-93.

Gudiña, E.J., Rodrigues, A.I., De Freitas, V., Azevedo, Z., José, A., Rodrigues, L.R., 2016b. Valorization of agro-industrial wastes towards the production of rhamnolipids. Bioresour. Technol. 212, 144-150.

Gustafsson, S., Hultberg, M., Figueroa, R.I., Rengefors, K., 2009. On the control of HAB species using low biosurfactant concentrations. Harmful Algae 8, 857863.

Hörmann, B., Müller, M.M., Syldatk, C., Hausmann, R., 2010. Rhamnolipid 
production by Burkholderia plantarii DSM 9509T. Eur. J. Lipid Sci. Technol. $112,674-680$.

471

472

473

474

475

476

477

478

479

480

481

482

483

484

485

486

487

488

489

490

491

492

493

Invally, K., Ju, L.K., 2017. Biolytic Effect of Rhamnolipid Biosurfactant and Dodecyl Sulfate Against Phagotrophic Alga Ochromonas danica. J. Surfactants Deterg. 20(5), 1161-1171.

Johann, S., Seiler, T.B., Tiso, T., Bluhm, K., Blank, L.M., Hollert, H., 2016. Mechanism-specific and whole-organism ecotoxicity of mono-rhamnolipids. Sci. Total Environ. 548-549, 155-263.

Kana, T.M., Geider, R.J., Critchley, C., 1997. Regulation of photosynthetic pigments in micro-algae by multiple environmental factors: a dynamic balance hypothesis. New Phytol. 137(4), 629-638.

Kłosowska-Chomiczewska, I.E., Medrzycka, K., Hallmann, E., Karpenko, E., Pokynbroda, T., Macierzanka, A., Jungnickel, C., 2017. Rhamnolipid CMC prediction. J. Colloid Interface. Sci. 488, 10-19.

Kourmentza, C., Costa, J., Azevedo, Z., Servin, C., Grandfils, C., De Freitas, V., Reis, M.A.M., 2018. Burkholderia thailandensis as a microbial cell factory for the bioconversion of used cooking oil to polyhydroxyalkanoates and rhamnolipids. Bioresour. Technol. 247, 829-837.

Kourmentza, C., Freitas, F., Alves, V., Reis, M.A.M., 2017. Microbial conversion of waste and surplus materials into high-value added products: the case of biosurfactants, in: Kalia, V.C., Kumar, P. (Eds.), Microbial Appications, Vol. 1 - Bioremediation and Bioenergy. Springer International Publishing, pp. 29-78.

Koutra, E., Grammatikopoulos, G., Kornaros, M., 2018. Selection of microalgae intended for valorization of digestate from agro-waste mixtures. Waste Manag. $73,123-129$. 
Kramer, N.I., Krismartina, M., Rico-Rico, A., Blaauboer, B.J., Hermens, J.L.M.,

495

496

497

498

499

500

501

502

503

504

505

506

507

508

509

510

511

512

513

514

515

516

517

518

2012. Quantifying processes determining the free concentration of phenanthrene in basal cytotoxicity assay. Chem. Res. Toxicol. 25, 436-445.

Kumar, S.K., Dahms, H.U., Lee, J.S., Kim, H.C., Lee, W.C., Shin, K.H., 2014. Algal photosynthetic responses to toxic metals and herbicides assessed by chlorophyll a fluorescence. Ecotoxicol. Environ. Saf. 104(1), 51-71.

Lowe, K.C., Davey, M.R., Laouar, L., Khatun, A., Ribeiro, R.C.S., Power, J.B., Mulligan, B.J., 1994. Surfactant stimulation of growth in cultured plant cells, tissues and organs, in: Lumsden, P.J., Nicholas, J.R., Davies, W.J. (Eds.), Physiology, growth and development of plants in culture, Springer, Dordrecht, pp. 234-244.

Ma, J.M., Cai, L.L., Zhang, B.J., Hu, L.W., Li, X.Y., Wang, J.J., 2010. Acute toxicity and effects of 1-alkyl-3-methylimidazolium bromide ionic liquids on green algae. Ecotoxicol. Environ. Saf. 73, 1465-1469.

Markets and Markets, 2017. Biosurfactants market by type (Glycolipids (Sophorolipids, Rhamnolipids), Lipopeptides, Phospholipids, Polymeric Biosurfactants), Application (Detergents, Personal Care, Agricultural Chemicals, Food Processing), and Region - Global Forecast to 2022.

Markwell, J.P., Thornber, J.P., 1982. Treatment of the thylakoid membrane with surfactants. Assessment of effectiveness using the chlorophyll alpha absorption spectrum. Plant Physiol. 70, 633-636

Maslin, P., Maier, R.M., 2000. Rhamnolipid-enhanced mineralization of phenanthrene in organic-metal co-contaminated soils. Bioremediat. J. 4, 295-308.

Müller, M.M., Kügler, J.H., Henkel, M., Gerlitzki, M., Hörmann, B., Pöhnlein, M., Syldatk, C., Hausmann, R., 2012. Rhamnolipids-Next generation surfactants? J. 
Biotechnol. 162, 366-380.

520

521

522

523

524

525

526

527

528

529

530

531

532

533

534

535

536

537

538

539

540

541

542

Nikookar, K., Moradshahi, A., Hosseini, L., 2005. Physiological responses of Dunaliella salina and Dunaliella tertiolecta to copper toxicity. Biomol. Eng. 22, $141-146$.

OECD, 2011. Test No. 201: Freshwater Alga and Cyanobacteria, Growth inhibition test, OECD guidelines for the testing of chemicals, section 2, OECD Publishing, Paris. DOI: http://dx.doi.org/10.1787/9789264069923-en

OJL 353, 2008. Regulation (EC) No 1272/2008 of the European Parliament and of the Council of 16 December 2008 on classification, labelling and packaging of substances and mixtures, amending and repealing Directives 67/548/EEC and 1999/45/EC, and amending Regulation (EC) No 1907/2006 (Text with EEA relevance). http://data.europa.eu/eli/reg/2008/1272/oj

Oren, A., 2005. A hundred years of Dunaliella research: 1095-2005. Sal. Systems 1, 2.

Oukarroum, A., Schansker, G., Strasser, R.J., 2009. Drought stress effects on photosystem I content and photosystem II thermotolerance analyzed using $\mathrm{Chl}$ a fluorescence kinetics in barley varieties differing in their drought tolerance. Physiol. Plant 137, 188-199.

Perreault, F., Matias, M.S., Oukarroum, A., Matias, W.G., Popovic, R., 2012. Okadaic acid inhibits cell growth and photosynthetic electron transport in the alga Dunaliella tertiolecta. Sci. Total Environ. 414, 198-204.

Popova, A., Kemp, R., 2007. Effects of surfactants on the ultrastructural organization of the phytoplankton, Chlamydomonas reinhardtii and Anabaena cylindrica. Fundam. Appl. Limnol/Arch. für Hydrobiol. 169(2), 131-136. 
543 Poremba, K., Gunkel, W., Lang, S., Wagner, F., 1991. Marine Biosurfactants, III. 544 Toxicity testing with marine microorganisms and comparison with synthetic surfactants. Z. Naturforsch. C 46(3-4), 210-216.

546 Ralph, P.J., Smith, R.A., Macinnis-Ng, C.M.O., Seery, C.R., 2007. Use of fluorescence-based ecotoxicological bioassays in monitoring toxicants and pollution in aquatic systems: review. Toxicol. Environ. Chem. 89(4), 589-607.

549 Saison, C., Perreault, F., Daigle, J.C., et al., 2010. Effect of core-shell copper oxide nanoparticles on cell culture morphology and photosynthesis (photosystem II energy distribution) in the green alga, Chlamydomonas reinhardtii. Aquat. Toxicol. 96(2), 109-114.

Sharma, C., Mathur, R., Tomar, R., Jajoo, A., 2018. Investigating role of Triton X100 in ameliorating deleterious effects of anthracene in wheat plants. Photosynthetica 56(2), 652-659.

Sobrinho, H.B., Luna, J.M., Rufino, R.D., Porto, A.L.F., Sarubbo, L.A., 2013. Biosurfactants: Classification, properties and environmental applications, in: Govil, J.N. (Ed.), Recent Developments in Biotechnology. $1^{\text {st }}$ ed. Vol 11. Studium Press LLC, Houston, TX, USA, pp. 1-29.

Strasser, R.J., Srivastava, A., Govindjee, 1995. Polyphasic chlorophyll a fluorescence transient in plants and cyanobacteria. Photochem. Photobiol. 61, 32-42.

Strasser, R.J., Srivastava, A., Tsimilli-Michael, M., 2000. The fluorescence transient as a tool to characterize and screen photosynthetic samples, in: Yunus, M., Pathre, U., Mohanty, P. (Eds.), Probing Photosynthesis: Mechanisms, Regulation and Adaptation, Taylor and Francis, London, pp. 445-483.

Strasser, R.J., Tsimilli-Michael, M., Srivastava, A., 2004. Analysis of the chlorophyll a fluorescence transient, in: Papageorgiou, G.C., Govindjee, (Eds.), Chlorophyll 
a fluorescence: a signature of photosynthesis, Springer Press, Netherlands, pp. $321-362$.

570 Stirbet, A., Govindjee, 2011. On the relation between the Kautsky effect (chlorophyll a fluorescence induction) and Photosystem II: Basics and applications of the OJIP fluorescence transient. J. Photochem. Photobiol. B 104, 236-257.

573 Tsarpali, V., Harbi, K., Dailianis, S., 2016. Physiological response of the green microalgae Dunaliella tertiolecta against imidazolium ionic liquids $[\mathrm{bmim}]\left[\mathrm{BF}_{4}\right]$ and/or $[\mathrm{omim}]\left[\mathrm{BF}_{4}\right]$ : the role of salinity on the observed effects. J. Appl. Phychol. 28, 979-990.

Tsiaka, P., Tsarpali, V., Ntaikou, I., Kostopoulou, M.N., Lyberatos, G., Dailianis, S., 2013. Carbamazepine-mediated pro-oxidant effects on the unicellular marine algal species Dunaliella tertiolecta and the hemocytes of mussel Mytilus galloprovincialis. Ecotoxicology 22, 1208-1220.

USEPA, 1974. Marine algal assay procedure bottle test: Eutrophication and Lake USA.

584 585

Vijayakumar, S., Saravanan, V., 2015. Biosurfactants-Types, Sources and Applications. Research Journal of Microbiology 10, 181-192.

Vonlanthen, S., Brown, M.T., Turner, A., 2011. Toxicity of the amphoteric surfactant, cocamidopropyl betaine, to the marine macroalga, Ulva lactuca. Ecotoxicology 20(1), 202-207.

Wang, X., Gong, L., Liang, S., Han, X., Zhu, C., Li, Y., 2005. Algicidal activity of rhamnolipid biosurfactants produced by Pseudomonas aeruginosa. Harmful Algae 4(2), 433-443. 
Wellburn, A.R., 1994. The spectral determination of chlorophylls a and b, as well as total carotenoids, using various solvents with spectrophotometers of different resolution. J. Plant Physiol. 144(3), 307-313.

Wen, J., Stacey, S.P., McLaughlin, M.J., Kirby, J.K., 2009. Biodegradation of rhamnolipid, EDTA and citric acid in cadmium and zinc contaminated soils. Soil Biol. Biochem. 41(10), 2214-2221.

Wittgens, A., Tiso, T., Arndt, T.T., Wenk, P., Hemmerich, J., Müller, C., Wichmann, R., Küpper, B., Zwick, M., Wilhelm, S., Hausmann, R., Syldatk, C., Rosenau, F., Blank, L.M., 2011. Growth independent rhamnolipid production from glucose using the non-pathogenic Pseudomonas putida KT2440. Microb. Cell. Fact. 10, 80 .

Xia, J., Tian, Q., 2009. Early stage toxicity of excess copper to photosystem II of Chlorella pyrenoidosa-OJIP chlorophyll a fluorescence analysis. J. Environ. Sci. 21(11), 1569-1574.

Young, E.B., Beardall, J., 2003. Photosynthetic function in Dunaliella tertiolecta (Chlorophyta) during a nitrogen starvation and recovery cycle. J. Phycol. 39(5), $897-905$.

Zeng, G.M., Fu, H.Y., Zhong, H., Yuan, X.Z., Fu, M.X., Wang, W., Huang, G.H., 2007. Codegradation with glucose of four surfactants, CTAB, Triton X-100, SDS and Rhamnolipid, in liquid culture media and compost matrix. Biodegradation 18, 303-310.

Zhang, Y., Maier, W.J., Miller, R.M., 1997. Effect of rhamnolipids on the dissolution, bioavailability and biodegradation of phenanthrene Environ. Sci. Technol., 31, 2211-2217. 
616 Zhou, W., Juneau, P., Qiu, B., 2006. Growth and photosynthetic responses of the 617 bloom-forming cyanobacterium Microcystis aeruginosa to elevated levels of $618 \quad$ cadmium. Chemosphere 65(10), 1738-1746. 


\section{FIGURE CAPTIONS}

620 Figure 1. Percentage of Dunaliella tertiolecta inhibition rate (\%I) after treatment for 621 24-96h with different concentrations of RLs. The results are mean \pm SDs from 2 622 independent experiments (each experiment was performed in duplicate). Values in 623 each column that share the same letter significantly differ from each other (Mann624 Whitney $U$ test, $\mathrm{p}<0.05)$.

625 Figure 2. Determination of (a) $\mathrm{Chl}$ a and (b) $\mathrm{Chl} \mathrm{b}$ in Dunaliella tertiolecta after 626 treatment for 24-96h with different concentrations of RLs. The results (expressed as 627 pg of chlorophyll per cell) are mean \pm SDs from 2 independent experiments (each 628 experiment was performed in duplicate). Values in each column that share the same 629 letter significantly differ from control (Mann-Whitney $U$ test, $p<0.05$ ).

630 Figure 3. Total chlorophyll content in Dunaliella tertiolecta after treatment for 24$63196 \mathrm{~h}$ with different concentrations of RLs. The results are mean \pm SDs from 2 632 independent experiments (each experiment was performed in duplicate). Values in 633 each column that share the same letter significantly differ from control (Mann634 Whitney $U$ test, $\mathrm{p}<0.05)$.

635 Figure 4. Concentration of carotenoids in Dunaliella tertiolecta after treatment for 636 24-96h with different concentrations of RLs. The results (expressed as pg of 637 carotenoids per cell) are mean \pm SDs from 2 independent experiments (each 638 experiment was performed in duplicate). Values in each column that share the same 639 letter significantly differ from control (Mann-Whitney $U$ test, $\mathrm{p}<0.05$ ). 
Table 1. Algal cell number (cells $\left./ \mathrm{mL} \times 10^{4}\right)$ and growth rate $(\mu$, within the parenthesis) after treatment for 24-96h with different concentrations of RLs. The results are mean \pm SDs from 2 independent experiments (each experiment was performed in duplicate). Values in each column that share the same letter significantly differ from each other (Mann-Whitney U test, $\mathrm{p}<0.05$ ).

\begin{tabular}{|c|c|c|c|c|}
\hline \multicolumn{5}{|c|}{ Treatment period (h) } \\
\hline$\underset{\left(\mathbf{m g ~ L}^{-1}\right)}{\operatorname{RLs}}$ & 24 & 48 & 72 & 96 \\
\hline $\mathbf{0}$ & $\begin{array}{c}2.38 \pm 0.05^{\mathrm{abcd}} \\
(0.87 \pm 0.02)\end{array}$ & $\begin{array}{c}3.29 \pm 0.23 \text { abcd } \\
(0.59 \pm 0.04)\end{array}$ & $\begin{array}{c}6.78 \pm 0.38 \text { abcd } \\
(0.64 \pm 0.02)\end{array}$ & $\begin{array}{c}10.12 \pm 0.29^{\mathrm{abcd}} \\
(0.58 \pm 0.01)\end{array}$ \\
\hline 5 & $\begin{array}{l}1.54 \pm 0.24^{\mathrm{a}} \\
(0.42 \pm 0.19)\end{array}$ & $\begin{array}{c}2.12 \pm 0.30^{\mathrm{aefg}} \\
(0.37 \pm 0.07)\end{array}$ & $\begin{array}{l}3.68 \pm 0.61^{\mathrm{a}} \\
(0.43 \pm 0.06)\end{array}$ & $\begin{array}{l}5.31 \pm 1.89^{\mathrm{a}} \\
(0.40 \pm 0.10)\end{array}$ \\
\hline 10 & $\begin{array}{l}1.29 \pm 0.32^{\mathrm{b}} \\
(0.23 \pm 0.04)\end{array}$ & $\begin{array}{l}1.64 \pm 0.27^{\text {be }} \\
(0.24 \pm 0.08)\end{array}$ & $\begin{array}{l}4.06 \pm 1.11^{\mathrm{b}} \\
(0.45 \pm 0.10)\end{array}$ & $\begin{array}{l}6.00 \pm 1.68^{\mathrm{be}} \\
(0.44 \pm 0.07)\end{array}$ \\
\hline 20 & $\begin{array}{l}1.22 \pm 0.14^{\mathrm{c}} \\
0.20 \pm 0.08)\end{array}$ & $\begin{array}{l}1.50 \pm 0.19^{\text {cf }} \\
0.20 \pm 0.06)\end{array}$ & $\begin{array}{l}3.31 \pm 1.35^{\mathrm{c}} \\
(0.37 \pm 0.16)\end{array}$ & $\begin{array}{l}3.68 \pm 1.36^{\mathrm{cef}} \\
(0.31 \pm 0.09)\end{array}$ \\
\hline 50 & $\begin{array}{l}1.12 \pm 0.23^{\mathrm{d}} \\
(0.10 \pm 0.14)\end{array}$ & $\begin{array}{l}1.25 \pm 0.27^{\mathrm{dg}} \\
(0.10 \pm 0.11)\end{array}$ & $\begin{array}{l}2.83 \pm 1.69^{\mathrm{d}} \\
(0.30 \pm 0.19)\end{array}$ & $\begin{array}{l}5.68 \pm 1.67^{\mathrm{df}} \\
(0.42 \pm 0.08)\end{array}$ \\
\hline
\end{tabular}


Table 2. Evaluation of $24-96 \mathrm{hIC}_{50}$ values (including confidence interval values within the parenthesis) after treatment with different concentrations of RLs (Probit, $\mathrm{p}<0.05$ ).

\begin{tabular}{ccc}
\hline $\begin{array}{c}\text { Treatment period } \\
\text { (h) }\end{array}$ & IC $_{\mathbf{5 0}}\left(\mathbf{m g ~ L}^{\mathbf{- 1}}\right)$ & $\begin{array}{c}\text { Hazard classification } \\
\text { (EC Regulation 1272/2008) }\end{array}$ \\
\hline 24 & $3.011(1.083-4.932)$ & \\
\hline 48 & $8.121(5.676-10.498)$ & \\
\hline 72 & $44.574(25.466-212.882)$ & $\begin{array}{c}\text { Chronic Category } 3 \\
>10 \text { to } \leq 100 \mathrm{mg} \mathrm{L}^{-1}\end{array}$ \\
\hline 96 & $>1000(\mathrm{ne})$ & \\
\hline
\end{tabular}

ne: not evaluated due to high variability of the algal response. 
Table 3. Photosynthetic parameters in Dunaliella tertiolecta, after treatment for a period of 24-96h with different concentrations of RLs. The results are mean \pm SDs from 2 independent experiments (each experiment was performed in duplicate). Values in each column that share the same letter significantly differ from the respective control (Mann-Whitney $U$ test, $\mathrm{p}<0.05$ ).

\begin{tabular}{|c|c|c|c|c|}
\hline RLs (mg/L) & \multicolumn{4}{|c|}{ Treatment period (h) } \\
\hline$\Phi P o$ or Fv/Fm & 24 & 48 & 72 & 96 \\
\hline 0 & $\mathbf{0 . 5 3} \pm 0.15$ & $\mathbf{0 . 6 5} \pm 0.01$ & $0.64 \pm 0.02$ & $\mathbf{0 . 6 7} \pm 0.03$ \\
\hline 5 & $\mathbf{0 . 5 3} \pm 0.16$ & $\mathbf{0 . 6 3} \pm 0.01$ & $\mathbf{0 . 6 3} \pm 0.01$ & $\mathbf{0 . 6 3} \pm 0.01$ \\
\hline 10 & $\mathbf{0 . 5 3} \pm 0.16$ & $\mathbf{0 . 6 4} \pm 0.01$ & $\mathbf{0 . 6 6} \pm 0.01$ & $\mathbf{0 . 6 5} \pm 0.02$ \\
\hline 20 & $\mathbf{0 . 5 0} \pm 0.17$ & $\mathbf{0 . 6 2} \pm 0.03$ & $\mathbf{0 . 6 5} \pm 0.02$ & $\mathbf{0 . 6 4} \pm 0.04$ \\
\hline 50 & $\mathbf{0 . 4 8} \pm 0.15$ & $\mathbf{0 . 6 2} \pm 0.02$ & $\mathbf{0 . 6 5} \pm 0.01$ & $\mathbf{0 . 6 4} \pm 0.01$ \\
\hline \multicolumn{5}{|l|}{ ФEo } \\
\hline $\mathbf{0}$ & $\mathbf{0 . 2 6} \pm 0.12$ & $\mathbf{0 . 3 7} \pm 0.02$ & $\mathbf{0 . 3 6} \pm 0.01$ & $\overline{\mathbf{0 . 3 6}} \pm 0.02$ \\
\hline 5 & $\mathbf{0 . 2 6} \pm 0.13$ & $\mathbf{0 . 3 4} \pm 0.01$ & $\mathbf{0 . 3 4} \pm 0.01$ & $\mathbf{0 . 3 1} \pm 0.02^{\mathrm{a}}$ \\
\hline 10 & $\mathbf{0 . 2 6} \pm 0.13$ & $\mathbf{0 . 3 6} \pm 0.01$ & $\mathbf{0 . 3 7} \pm 0.01$ & $\mathbf{0 . 3 4} \pm 0.01$ \\
\hline 20 & $\mathbf{0 . 2 4} \pm 0.13$ & $\mathbf{0 . 3 4} \pm 0.03$ & $\mathbf{0 . 3 5} \pm 0.02$ & $\mathbf{0 . 3 3} \pm 0.05$ \\
\hline 50 & $\mathbf{0 . 2 4} \pm 0.13$ & $\mathbf{0 . 3 3} \pm 0.03$ & $\mathbf{0 . 3 6} \pm 0.01$ & $\mathbf{0 . 3 2} \pm 0.01^{\mathrm{a}}$ \\
\hline \multicolumn{5}{|l|}{$\varphi \mathrm{R0}$} \\
\hline $\mathbf{0}$ & $\mathbf{0 . 1 0} \pm 0.06$ & $\mathbf{0 . 1 4} \pm 0.02$ & $\mathbf{0 . 1 4} \pm 0.01$ & $\mathbf{0 . 1 4} \pm 0.01$ \\
\hline 5 & $\mathbf{0 . 0 9} \pm 0.05$ & $\mathbf{0 . 1 4} \pm 0.01$ & $\mathbf{0 . 1 3} \pm 0.01$ & $\mathbf{0 . 1 3} \pm 0.01$ \\
\hline 10 & $\mathbf{0 . 0 9} \pm 0.06$ & $\mathbf{0 . 1 4} \pm 0.01$ & $\mathbf{0 . 1 3} \pm 0.00$ & $\mathbf{0 . 1 3} \pm 0.01$ \\
\hline 20 & $\mathbf{0 . 0 9} \pm 0.06$ & $\mathbf{0 . 1 3} \pm 0.02$ & $\mathbf{0 . 1 2} \pm 0.00^{\mathrm{a}}$ & $\mathbf{0 . 1 1} \pm 0.02^{\mathrm{a}}$ \\
\hline 50 & $\mathbf{0 . 1 1} \pm 0.07$ & $\mathbf{0 . 1 4} \pm 0.03$ & $\mathbf{0 . 1 2} \pm 0.00^{\mathrm{a}}$ & $\mathbf{0 . 1 1} \pm 0.01^{\mathrm{a}}$ \\
\hline \multicolumn{5}{|l|}{$1-V_{I}$} \\
\hline$\overline{0}$ & $\mathbf{0 . 1 7} \pm 0.06$ & $0.22 \pm 0.02$ & $0.22 \pm 0.03$ & $\mathbf{0 . 2 1} \pm 0.02$ \\
\hline 5 & $\mathbf{0 . 1 6} \pm 0.05$ & $\mathbf{0 . 2 3} \pm 0.02$ & $\mathbf{0 . 2 0} \pm 0.01$ & $\mathbf{0 . 2 1} \pm 0.02$ \\
\hline 10 & $\mathbf{0 . 1 6} \pm 0.06$ & $\mathbf{0 . 2 2} \pm 0.02$ & $\mathbf{0 . 2 0} \pm 0.00$ & $\mathbf{0 . 2 0} \pm 0.01$ \\
\hline 20 & $\mathbf{0 . 1 6} \pm 0.07$ & $\mathbf{0 . 2 1} \pm 0.02$ & $\mathbf{0 . 1 8} \pm 0.00$ & $\mathbf{0 . 1 7} \pm 0.01^{\mathrm{a}}$ \\
\hline 50 & $\mathbf{0 . 2 0} \pm 0.09$ & $\mathbf{0 . 2 3} \pm 0.04$ & $\mathbf{0 . 1 8} \pm 0.00$ & $\mathbf{0 . 1 7} \pm 0.01^{\mathrm{a}}$ \\
\hline \multicolumn{5}{|l|}{ PItotal } \\
\hline $\mathbf{0}$ & $\mathbf{0 . 2 6} \pm 0.26$ & $\mathbf{0 . 4 4} \pm 0.15$ & $\mathbf{0 . 3 9} \pm 0.07$ & $\mathbf{0 . 4 0} \pm 0.04$ \\
\hline 5 & $\mathbf{0 . 2 2} \pm 0.22$ & $\mathbf{0 . 3 8} \pm 0.08$ & $\mathbf{0 . 3 1} \pm 0.03^{\mathrm{a}}$ & $\mathbf{0 . 2 9} \pm 0.07$ \\
\hline 10 & $\mathbf{0 . 2 4} \pm 0.24$ & $\mathbf{0 . 3 9} \pm 0.09$ & $\mathbf{0 . 3 5} \pm 0.04$ & $\mathbf{0 . 3 1} \pm 0.05^{\mathrm{a}}$ \\
\hline 20 & $\mathbf{0 . 2 2} \pm 0.23$ & $\mathbf{0 . 3 2} \pm 0.14$ & $\mathbf{0 . 3 0} \pm 0.04^{\mathrm{a}}$ & $0.23 \pm 0.10^{\mathrm{a}}$ \\
\hline 50 & $\mathbf{0 . 2 9} \pm 0.32$ & $\mathbf{0 . 3 4} \pm 0.14$ & $0.29 \pm 0.03^{\mathrm{a}}$ & $\mathbf{0 . 2 1} \pm 0.04^{\mathrm{a}}$ \\
\hline
\end{tabular}



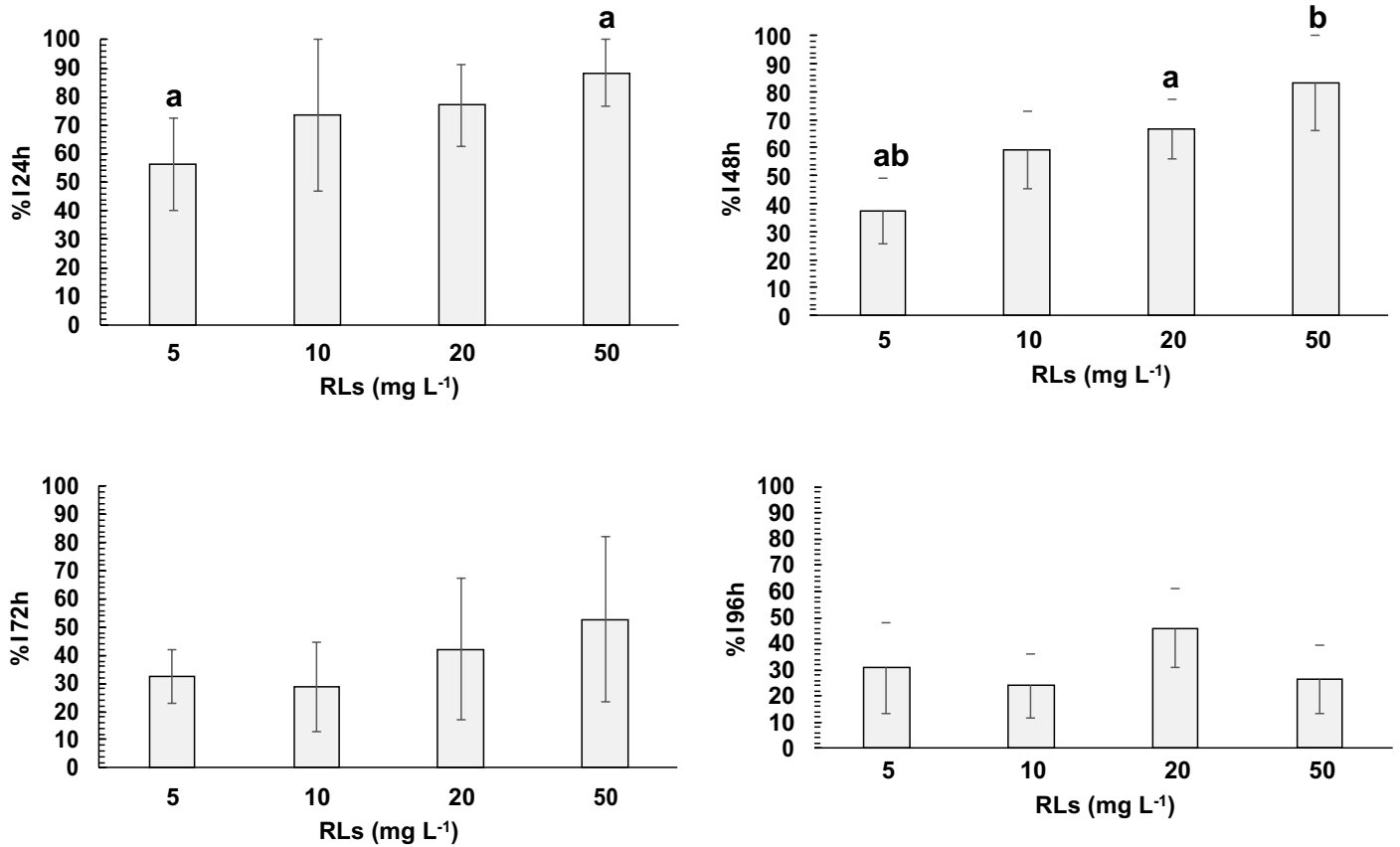

Fig 1. 

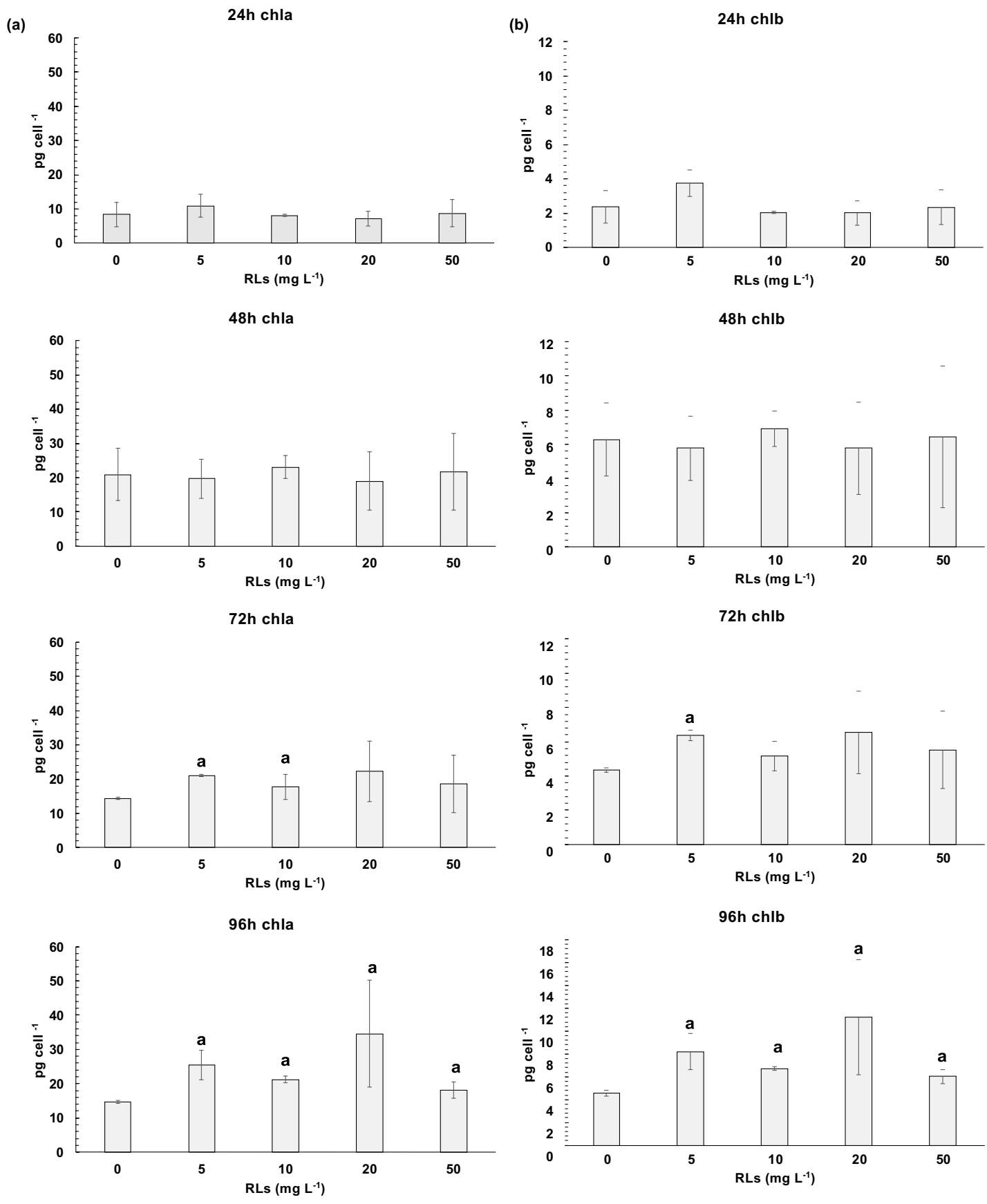

Fig 2. 

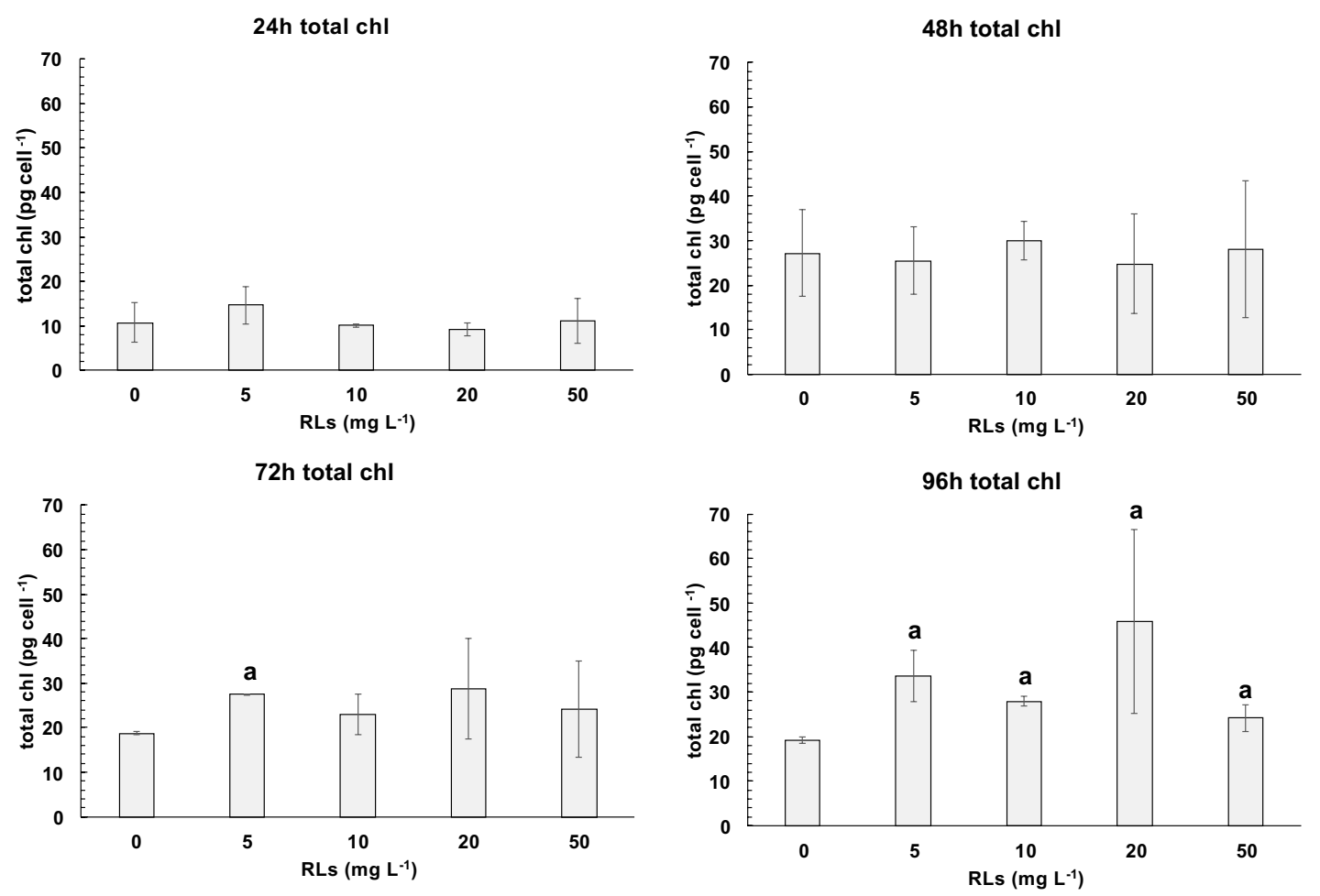

Fig 3. 

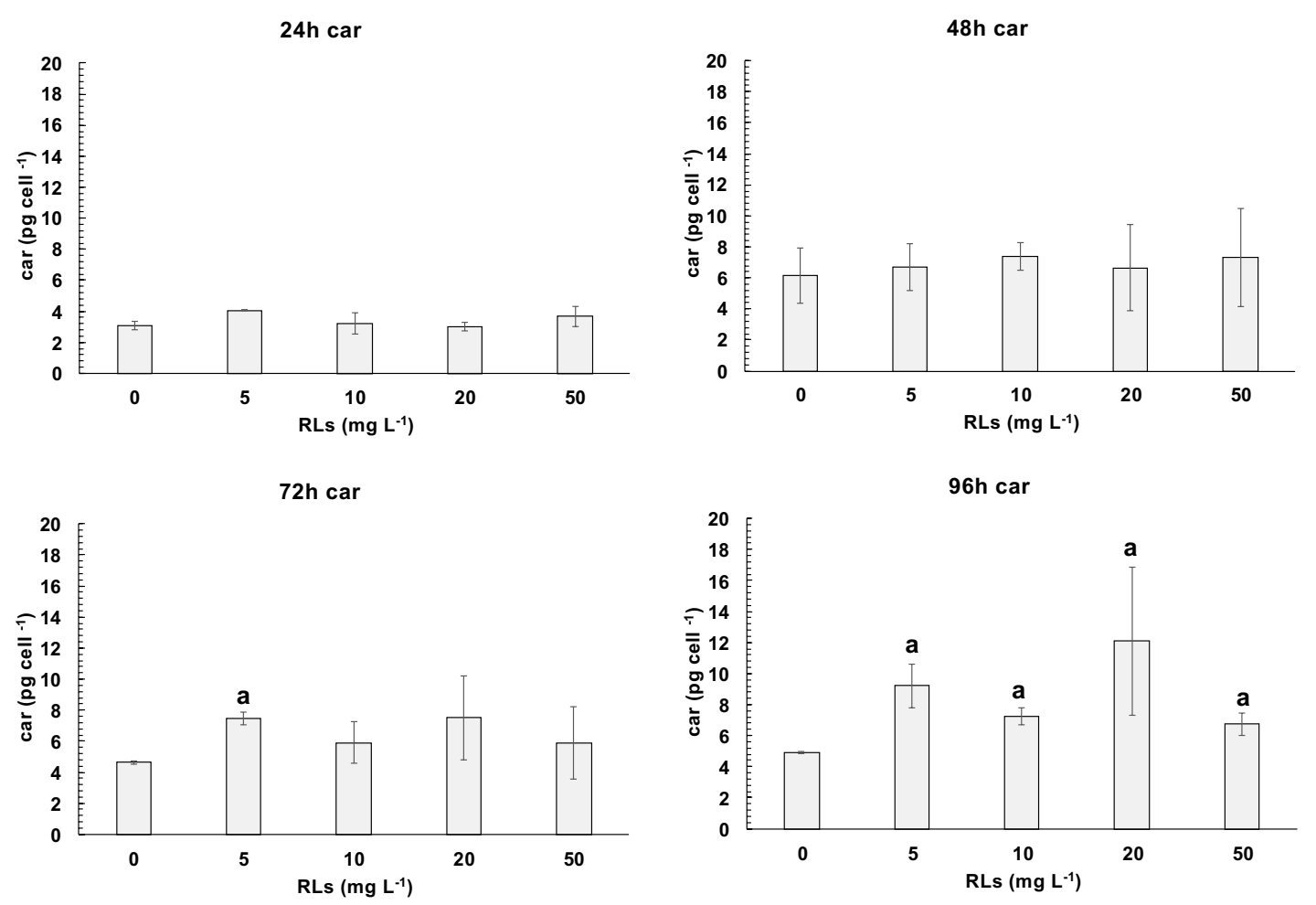

Fig 4. 
Supplementary material

\section{Effects of Burkholderia thailandensis rhamnolipids on the unicellular algae}

\section{Dunaliella tertiolecta.}

Nikolina Charalampous ${ }^{1}$, Giorgos Grammatikopoulos ${ }^{2}$, Constantina Kourmentza ${ }^{3}$, Michael Kornaros ${ }^{4}$, Stefanos Dailianis ${ }^{1^{*}}$

${ }^{1}$ Section of Animal Biology, Department of Biology, Faculty of Sciences, University of Patras, 26500, GR Patras, Greece.

${ }^{2}$ Laboratory of Plant Physiology, Section of Plant Biology, Department of Biology, Faculty of Sciences, University of Patras, GR 26500, Patras, Greece.

${ }^{3}$ Department of Food \& Nutritional Sciences, School of Chemistry, Food and Pharmacy, University of Reading, RG6 6AP, Reading, UK

${ }^{4}$ Laboratory of Biochemical Engineering and Environmental technology (LBEET), Department of Chemical Engineering, University of Patras, Karatheodori 1 St, GR 26500 Patras, Greece

${ }^{*}$ Corresponding author:

Tel.: $+32610-969213$

E-mail: $\underline{\text { sdailianis@upatras.gr }}$

Section of Animal Biology

Department of Biology

Faculty of Sciences, University of Patras

GR-26 500 PATRAS, GREECE 


\section{Table of contents}

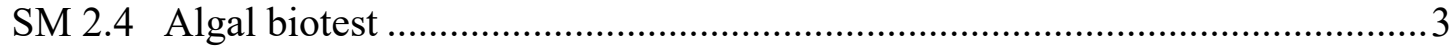

SM 2.5 Determination of chlorophyll content and total carotenoids .......................... 3

SM Figure 1. Chl a/Chl b ratio in Dunaliella tertiolecta after treatment for 24-96h with different concentrations of RLs. The results are mean \pm SDs from 2 independent experiments (each experiment was performed in duplicate) ....................................... 4

SM Figure 2. Carotenoids/total chlorophyll ratio in Dunaliella tertiolecta after treatment for 24-96h with different concentrations of RLs. The results are mean \pm SDs from 2 independent experiments (each experiment was performed in duplicate) 5 
SM 2.4 Algal biotest

The algal cell number was counted, using a Neubauer hemocytometer, while the growth $(\mu)$ and the inhibition rate $(\% \mathrm{I})$ were determined according to equations (1) and (2).

$$
\mu_{n}=\frac{\ln X_{n}-\ln X_{0}}{t_{n}-t_{0}}
$$

$\mu_{n}$ : algal growth rate $\left(\right.$ day $\left.^{-1}\right)$ after $n$ days $(24,48,72$ or $96 \mathrm{~h})$

$X_{0}=$ number of cells $/ \mathrm{ml}$ at time $0\left(\mathrm{t}_{0}\right)$

$X_{n}=$ number of cells $/ \mathrm{ml}$ at $\mathrm{t}_{\mathrm{n}}$

$t_{0}=$ time of first measurement after beginning of test

$t_{n}=$ time of nth measurement after beginning of test

$$
\% I=\frac{\mu_{c}-\mu_{n}}{\mu_{c}} \times 100
$$

$\% I:$ percent inhibition in average specific growth rate

$\mu_{c}$ : mean value for average specific growth rate $(\mu)$ in the control group $\mu_{n}$ : average specific growth rate for the treatment replicate.

SM 2.5 Determination of chlorophyll content and total carotenoids

Chl a, Chl b and total carotenoids content $\left(\mu \mathrm{g} \mathrm{mL}{ }^{-1}\right)$ was calculated using the Lambert-Beer based equations (3-5) (Wellburn, 1994).

$$
\begin{aligned}
& \mathrm{C}_{\mathrm{a}}=11.65 \mathrm{~A}_{664}-2.69 \mathrm{~A}_{647} \\
& \mathrm{C}_{\mathrm{b}}=20.81 \mathrm{~A}_{647}-4.53 \mathrm{~A}_{664} \\
& \mathrm{C}_{\mathrm{x}+\mathrm{c}}=\left(1000 \mathrm{~A}_{480}-0.89 \mathrm{C}_{\mathrm{a}}-52.02 \mathrm{C}_{\mathrm{b}}\right) / 245
\end{aligned}
$$



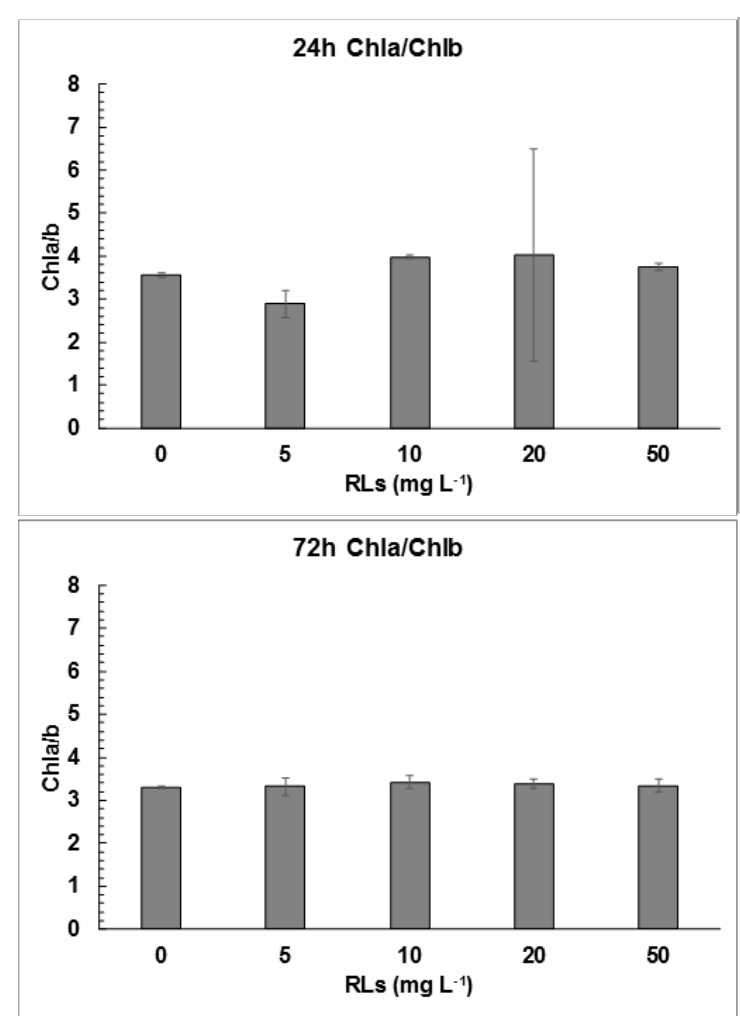

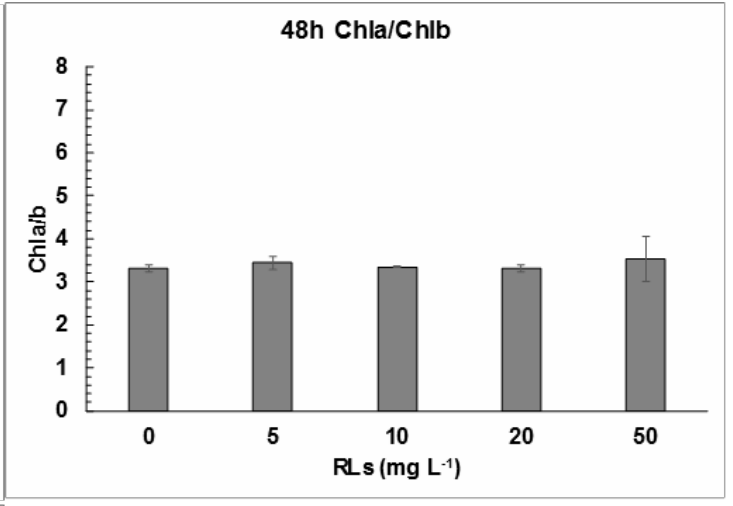

96h Chla/Chlb

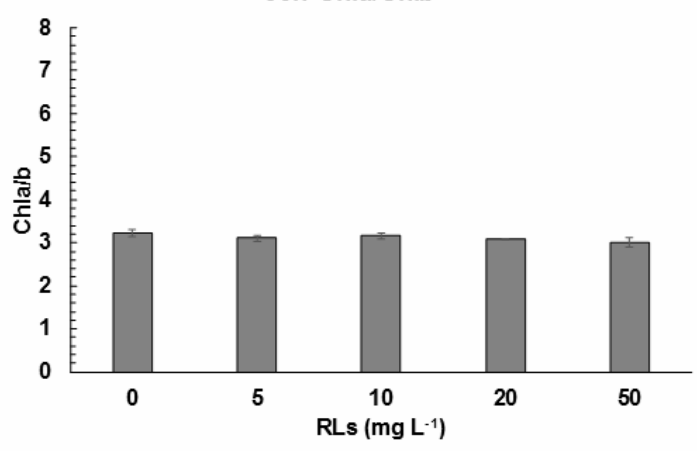

SM Figure 1. Chl a/Chl b ratio in Dunaliella tertiolecta after treatment for $24-96 \mathrm{~h}$ with different concentrations of RLs. The results are mean \pm SDs from 2 independent experiments (each experiment was performed in duplicate). 

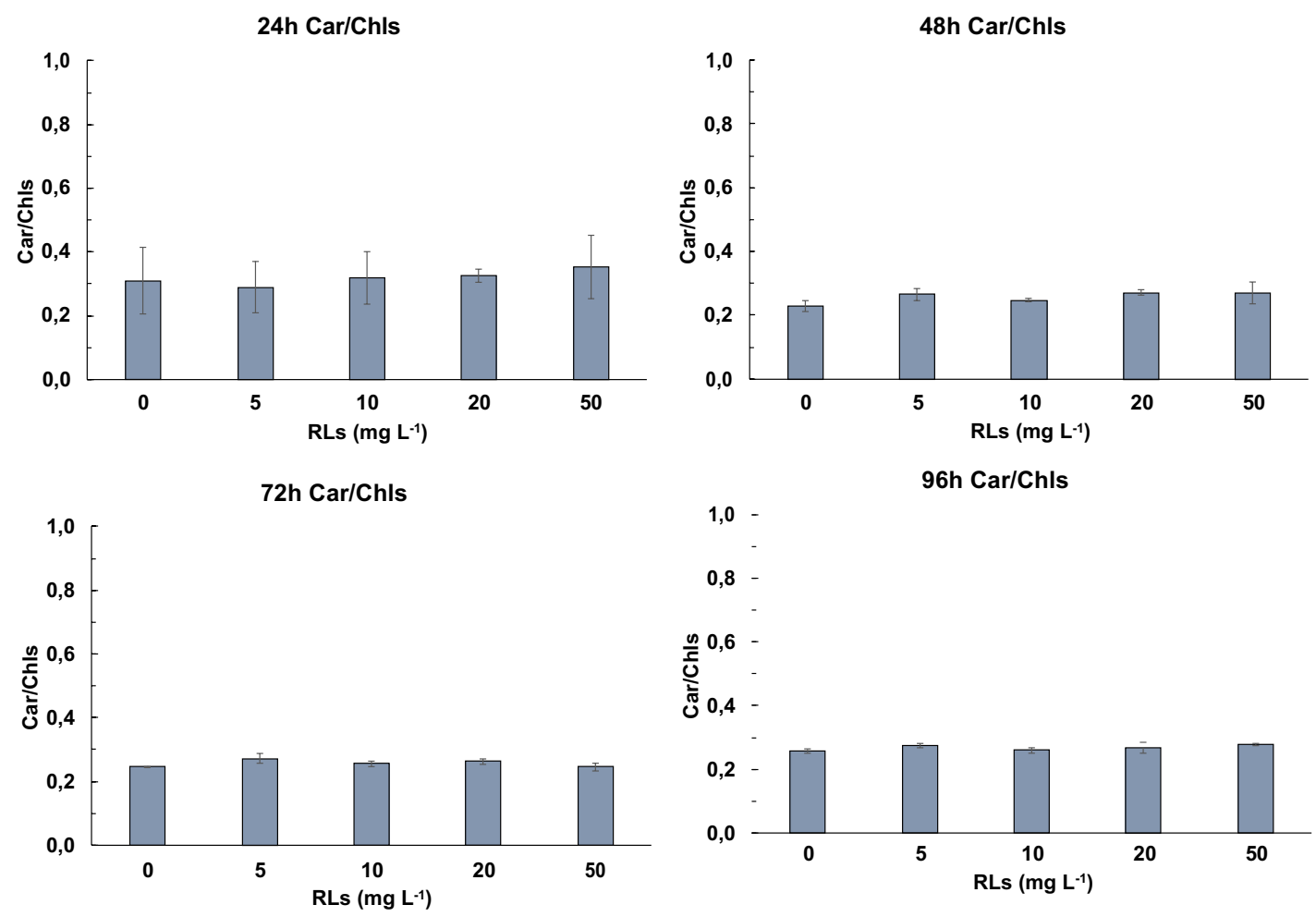

SM Figure 2. Carotenoids/total chlorophyll ratio in Dunaliella tertiolecta after treatment for 24-96h with different concentrations of RLs. The results are mean \pm SDs from 2 independent experiments (each experiment was performed in duplicate). 